Quim. Nova, Vol. 31, No. 3, 694-699, 2008

\title{
O ESPAÇO DA PRÁTICA DE ENSINO E DO ESTÁGIO CURRICULAR NOS CURSOS DE FORMAÇÃo DE PROFESSORES DE QUÍMICA DAS IES PÚBLICAS PAULISTAS
}

\author{
Ana Cláudia Kasseboehmer* e Luiz Henrique Ferreira \\ Departamento de Química, Universidade Federal de São Carlos, CP 676, 13560-970 São Carlos - SP, Brasil
}

Recebido em 29/1/07; aceito em 21/9/07; publicado na web em 10/3/08

\begin{abstract}
THE PLACE OF TEACHING PRACTICE AND INTERNSHIP IN THE CHEMISTRY COURSES LEADING TO TEACHING CREDENTIALS AT THE STATE UNIVERSITIES OF SÃO PAULO. The literature presents a new understanding of the teaching practice and the supervised internship.Mutual interaction between them is expected one providing subsidies to the other.The present article shows the conceptions prevailing at the São Paulo state universities regarding these activities.Students, when interviewed, report difficulties in dealing with classroom situations. It is possible to observe that chemists wish to prepare new chemists deviating from the objectives of a Chemistry course leading to teaching credentials .
\end{abstract}

Keywords: initial formation; teaching practice; internship.

\section{INTRODUÇÃOO}

Desde sua criação, a disciplina Prática de Ensino de Química e Estágio Supervisionado (PEES) era considerada como a disciplina do curso de licenciatura na qual as atividades de prática de ensino e as de estágio supervisionado aconteciam. Nesta disciplina, geralmente oferecida nos dois últimos semestres do curso, os objetivos almejados para uma e outra atividade eram confundidos, sendo ambas as atividades entendidas como um espaço prático - o de realização do estágio - onde a teoria pedagógica aprendida deveria ser aplicada. Alguns pareceres governamentais referiram-se a essas atividades com o objetivo de melhorar a qualidade dos cursos de formação de professores, entretanto, apesar das diversas tentativas, os resultados práticos foram pontuais, geralmente por resolverem apenas uma face do problema.

Para exemplificar, o Parecer CFE nº 349 de 1972 representa uma tentativa de superação da dicotomia teoria-prática ao determinar que a Didática (aprendizagem da teoria) e PEES (aplicação na prática) fossem cursadas concomitantemente. ${ }^{1}$ Já o Parecer CFE $\mathrm{n}^{\circ} .4 .873$ de 1975 preocupou-se em integrar os conteúdos e os métodos, determinando que PEES fosse ministrada por um professor da área de conteúdo específico. ${ }^{1}$

Em relação às atividades desenvolvidas nessas disciplinas, Dall'Orto aponta que era freqüente o uso do micro-ensino - atividades de regência fora dos espaços escolares reais em situações controladas de ensino - regido pela psicologia comportamentalista. Nessa perspectiva, o licenciando deveria aplicar técnicas prontas de ensino; a aprendizagem efetiva ocorreria com a aplicação correta de tais técnicas e assim, o aluno aprenderia a ser um bom professor. Essa metodologia, chamada de modelo da redescoberta, visava superar o sistema tradicional de ensino pela utilização "dos preceitos da Racionalidade Técnica, pois a redescoberta tornou-se uma técnica de ensinar conteúdos prontos através de uma aula prática." ${ }^{1}$ (p. 16)

\section{OS OBJETIVOS DAS ATIVIDADES DE PRÁTICA DE ENSINO E DE ESTÁGIO CURRICULAR}

Atualmente, as pesquisas na área educacional buscam integrar as

*e-mail: claudiaka@gmail.com atividades de prática de ensino e de estágio supervisionado visando uma interação entre teoria e prática, não no sentido dicotômico anteriormente atribuído a elas no qual na prática aplicava-se à teoria aprendida. A nova concepção atribuída a essas atividades conduz a uma interação mútua em que uma fornece subsídios à outra com a finalidade de promover a aprendizagem da atuação docente pelos licenciandos.

Piconez confere uma relação dialética entre a prática de ensino e o estágio curricular, de modo que a este reserva uma dimensão prática e real a partir do contexto da educação brasileira, enquanto que àquela confere uma dimensão teórica e ideal. ${ }^{2}$ Segundo Pimenta, ${ }^{3}$ a teoria é o único meio pelo qual a realidade pode ser compreendida, fornecendo, também, subsídios para sua transformação. Entretanto, a autora explica que essa transformação não acontece na teoria: é no processo prático que os elementos teóricos são verificados e apropriados. É nessa perspectiva que toma sentido a prática da reflexão no processo formativo, ${ }^{4}$ visto que a articulação entre teoria e prática se efetiva na atividade reflexiva de compreensão da situação prática e na transformação desta através de elementos aprendidos teoricamente, num movimento dialético. ${ }^{2}$ Dessa forma, a atividade docente ganha um novo componente, no qual os (futuros) professores se tornam pesquisadores de sua própria prática, ${ }^{5}$ produzindo sua própria identidade como profissionais. Quando a prática e a teoria são trabalhadas dessa maneira, a teoria deixa de ser percebida como explicações vazias que parecem não ser aplicáveis numa situação real de sala de aula. Tampouco, a prática não mais é tomada como uma experiência isolada impassível de ser entendida e trabalhada teoricamente. Além disso, o contato com futuras situações de trabalho possibilita aos licenciandos tornarem-se mais confiantes em relação ao seu conhecimento e ao comportamento que pretendem apresentar quando entrarem de fato nessa profissão, superando os medos e as inseguranças que acompanham estudantes de licenciatura durante a execução do estágio, como constatado por Lima ${ }^{6}$ para estudantes de Pedagogia.

Piconez explica que nessa compreensão dialética de prática de ensino e de estágio, as atividades não podem ser rigidamente programadas com antecedência, o que conduziria a uma concepção de professor como executor de planos de ensino. Além disso, a prática de ensino incorpora um caráter provisório, no qual a consciência sobre a finalidade da educação e os métodos necessários para as atividades de ensino são apreendidos a partir de reflexões contínu- 
as entre os (futuros) educadores. ${ }^{2}$

$\mathrm{O}$ que se pretende em atividades de prática de ensino - seja na observação de como atuam professores em exercício, seja com a utilização de vídeos contendo momentos de ensino - e de estágio supervisionado é proporcionar bagagem ao licenciando. Na vivência de distintas situações-problema de ensino com metodologias de atuação nas mesmas sob diferentes perspectivas, o estagiário poderá adquirir não um modelo teórico único que dê conta de todas as situações de ensino, mas sim escolhas e atitudes alternativas para lidar com diversos tempos de aprendizagem e comportamentos dos alunos. ${ }^{7}$

Entretanto, normalmente a dinâmica dos cursos de formação limita-se à questão da organização das atividades de ensino em detrimento da ação e da reflexão, estratégia esta que conduz à formação de um professor técnico. ${ }^{8}$ Formando-se professores sob essa perspectiva, quando o licenciando for inserido na prática, ao deparar-se com uma situação inédita a qual não esteja inserida em seu repertório de soluções técnicas tão somente, o mesmo não saberá como agir. ${ }^{1}$

No que concerne às atividades relacionadas à formação do professor, esta necessita direcionar a ação dos estudantes para a tentativa e a análise. O objetivo da análise da tentativa aplicada é o retorno à ação para nova verificação a respeito da eficácia da metodologia escolhida. É necessário dotar os estagiários de um estoque de experiências que poderá ser retomado quando da sua atuação profissional. ${ }^{7}$ Aumentar o estoque de rotinas, mas, para além disso, acolher e tratar de forma pertinente toda informação proveniente de sua turma; ou seja, aprender mecanismos de reflexividade e ferramentas para captar informações.

Segundo Perrenoud, é importante que os licenciandos vivenciem diferentes etapas durante o curso de modo a iniciá-lo na rotina do exercício docente. São essas fases: ${ }^{9}$ aprender a ver e analisar - enquadrando-se aqui o que diz respeito a conhecer as estratégias de professores experientes e a rotina de uma sala de aula; aprender a ler, ouvir e explicar - o que compete interpretar a observação da realidade, confrontar seus distintos elementos constitutivos e explicitar suas próprias reflexões; aprender a fazer - como um primeiro momento da aquisição dos saberes práticos, onde ocorre a experimentação das estratégias aprendidas teoricamente, mas com o respaldo dos formadores para lidar com as aflições e inseguranças do licenciando; aprender a refletir - sendo que é necessário que a reflexão sobre a prática se torne um hábito não apenas após a prática, mas que aconteça naturalmente no momento da ação; transpor para a formação profissional correspondendo a transformar os saberes eruditos e técnicos, tornando-os acessíveis ao aprendiz. Aqui se ressalta a importância dos formadores cujo repertório é mais amplo que o do licenciando, sendo um tanto mais fácil reinterpretar a teoria na tentativa de utilizá-la na aquisição de habilidades profissionais.

O último item enquadra um importante aspecto a ser trabalhado nos cursos de formação de professores. Essas aprendizagens relacionam-se à integração entre os conhecimentos pedagógicos e os de conteúdo químico, ou seja, a discussão a respeito de como o conhecimento educacional pode ser utilizado para o ensino e a aprendizagem de conhecimento químico. Esta é uma ponte importante e que necessariamente deve ser considerada nos cursos de licenciatura, visto que a formação do professor não se limita às teorias pedagógicas e tampouco às teorias químicas, mas principalmente como ambos os conhecimentos podem ser aproveitados para o exercício da profissão em sala de aula. Exercícios voltados para o planejamento de atividade, sua aplicação em sala de aula e a posterior reflexão sobre esse processo têm se mostrado um bom recurso para os licenciandos melhorarem até mesmo seu próprio nível de conhecimento na sua área específica. ${ }^{10}$

Pensando a respeito do tempo necessário, em um curso de graduação, para essa formação teorico-prática do licenciando como educador, Fávero contribui ao defender que o simples fato de conhecer teorias produzidas ou reconhecer os problemas da profissão não são suficientes para formar o indivíduo como profissional. ${ }^{11}$ Segundo a autora, é necessário desenvolver no licenciando um posicionamento crítico no qual ele construa sua própria prática, a partir de subsídios fornecidos pelo curso de graduação. Para alcançar esse objetivo, momentos que propiciem o desenvolvimento dessa atitude precisam permear o curso não pontualmente, mas ocupando um de seus espaços principais.

\section{A DISTRIBUIÇÃO DE CARGA HORÁRIA PARA OS CURSOS DE LICENCIATURA}

Compreendendo-se os diferentes aspectos que um curso de licenciatura necessita atender, em concordância com o que apregoam os pesquisadores da área de formação de professores, novas legislações, ${ }^{12,13}$ agora de maneira ampla e profunda, determinam as normas a serem atendidas por esses cursos. Nesse sentido, a carga horária mínima dos cursos de licenciatura deve ser distribuída como segue: ${ }^{13} 1800 \mathrm{~h}$ de aulas para os conteúdos curriculares de natureza científico-cultural; $200 \mathrm{~h}$ para outras formas de atividades acadêmico-científico-culturais (AACC); $400 \mathrm{~h}$ de prática de ensino como componente curricular (PECC) e, 400 h de estágio supervisionado como componente curricular (EC).

Para as 1800 h espera-se que sejam trabalhados tanto os conhecimentos recomendados para a formação de químico, como determinam as Diretrizes Curriculares para os Cursos de Química, ${ }^{14,15}$ quanto os conhecimentos pedagógicos necessários à formação do professor. As $200 \mathrm{~h}$ de AACC têm por objetivo ampliar a cultura do estudante, estimulando-o a freqüentar espaços acadêmicos, científicos e culturais.

Em relação às atividades de PECC e EC, a carga horária foi separada em dois blocos de $400 \mathrm{~h}$ cada, sendo um deles para PECC e outro para EC. Essa divisão busca esclarecer a diferenciação existente entre as atividades de prática de ensino e as de estágio supervisionado. No que se refere às atividades práticas do curso, são designadas prática como componente curricular que deve estar presente em toda a grade curricular. ${ }^{12}$ Essa atitude tem o intuito de superar a idéia de que apenas a disciplina de estágio é a responsável pela reflexão dos aspectos que envolvem a profissão de professor; o estágio curricular deve ocorrer apoiado nas reflexões ocorridas durante todo o curso. Nesse sentido, todos os formadores do curso de licenciatura tornam-se responsáveis por propiciar momentos de discussão que contribuam para a formação do licenciando, nas atividades de PECC. ${ }^{12}$

Assim, são normalizadas $400 \mathrm{~h}$ para as atividades de PECC, que deve permear todo o curso, desde seu início, sendo flexível para que possa atender aos diversos aspectos da formação do professor. ${ }^{13}$ Além disso, a prática deve transcender a sala de aula, envolvendo, também, ambientes escolares e seus órgãos administrativos. A prática deve ainda estar estreitamente vinculada tanto ao estágio curricular quanto às atividades acadêmicas, contribuindo para a formação de uma identidade de professor. As concepções e entendimentos das instituições formadoras em relação a como essas cargas horárias serão trabalhadas durante o curso devem estar explicitadas e detalhadas no projeto pedagógico de cada curso. ${ }^{13}$

Já em relação ao estágio curricular, esse é um momento de capacitação em serviço sob a obrigatória supervisão de um profissional já habilitado e reconhecido na área. Esse estágio possui carga horária de $400 \mathrm{~h}$, devendo iniciar a partir da segunda metade do curso. A dedicação ao estágio deverá ser densa e contínua em todo esse período. ${ }^{12}$

Nessas atividades de estágio curricular supervisionado, os estagiários devem de fato assumir o papel de professor na sala de aula. ${ }^{12}$ 
Além disso, a legislação determina que o aluno necessita tomar contato com as outras peculiaridades do ambiente escolar que exigirão adaptação e flexibilidade desse futuro profissional. Como exemplo, atividades de preparação do projeto pedagógico, organização de turmas e calendário, entre outros. Essas atividades englobam a tríade licenciando-formador-professor em exercício, a qual deve ser respeitada para a satisfação da formação profissional do futuro professor.

Uma vez que é necessária a abertura da instituição escolar secundária para a realização do estágio, o documento aponta para a necessidade do retorno por parte da instituição formadora. Esse retorno pode ocorrer na forma de cursos de formação continuada para os docentes da escola e outras atividades integradoras entre esses dois ambientes formativos. ${ }^{12}$

Tendo-se em vista a importância das atividades de prática de ensino e de estágio supervisionado para a boa formação dos professores de Química, o objetivo deste trabalho é explicitar as concepções existentes nas IES públicas paulistas a respeito dessas atividades como forma de contribuir para uma reflexão sobre os diferentes meios de contemplar a legislação vigente. Essa verificação é realizada a partir da distribuição da carga horária nas grades curriculares dos cursos, buscando-se compreender as concepções institucionais sobre o processo de formação de professores de Química.

\section{METODOLOGIA}

Salvo pela necessidade de cumprir com as exigências impostas por órgãos superiores - por exemplo, o Conselho Estadual de Educação ${ }^{16}$ ao qual as universidades estaduais paulistas estão subordinadas - ou pela legislação educacional, as IES públicas paulistas gozam de certa liberdade na composição de suas grades curriculares. Esse fato possibilita a elaboração de diferentes estruturas de cursos, o que por sua vez permite a inferência a respeito das concepções institucionais que permeiam uma ou outra escolha para formação de determinado profissional e que se encontram refletidas nessas grades curriculares.

Dessa maneira, os dados utilizados neste trabalho constam das grades curriculares coletadas durante uma pesquisa de mestrado no ano de 2005 envolvendo os nove cursos de licenciatura em Química das IES públicas paulistas. ${ }^{17}$ As discussões deste texto acerca das concepções institucionais sobre formação de professores de Química são ilustradas com algumas percepções levantadas junto a professores e alunos nas entrevistados para a pesquisa de mestrado supracitada.

\section{RESULTADOS E DISCUSSÃO}

Na Tabela 1 encontra-se a distribuição da carga horária apre- sentada por cada curso de licenciatura em Química das universidades públicas paulistas, na qual estão inseridas as $400 \mathrm{~h}$ para atividades de prática de ensino, bem como as $400 \mathrm{~h}$ para atividades de estágio supervisionado. Nesta tabela, QT (h) representa a carga horária de disciplinas teóricas de conteúdo químico; QP (h) representa a carga horária de disciplinas experimentais de conteúdo químico; em Outras (h) encontra-se a carga horária de disciplinas que contribuem para a formação do licenciando, mas que não têm definição rígida na legislação. Naqueles cursos em que as atividades de PECC não são discriminadas nem na grade curricular, nem no projeto pedagógico do curso, foram consideradas como PECC disciplinas de interface entre os conteúdos pedagógicos e os químicos. Após ter sido feita a distribuição de cargas horárias constantes da tabela, os coordenadores dos respectivos cursos foram consultados sobre possíveis incorreções.

Apesar de não haver diferenças significativas na carga horária total de cada curso, que têm em média 3492 h (o mínimo determinado por lei é $2800 \mathrm{~h}$ ), pode-se perceber que existem diferentes concepções institucionais a respeito de como deve ser feita a distribuição da carga horária total e, portanto, que existem também distintas maneiras de se compreender a formação do professor.

Observando-se os dados da Tabela 1, nota-se que as instituições reservaram cargas horárias bastante distintas para as disciplinas de conhecimento químico. Essa carga horária varia de 390 a 1350 h, sendo que a grande maioria desses cursos cumpre com as determinações legais que tratam da aquisição de conhecimentos de química, conforme discriminados pelas Diretrizes Curriculares para formação do químico. ${ }^{14,15}$ Essas diferenças institucionais também podem ser encontradas comparando-se as cargas horárias destinadas às disciplinas teóricas e às disciplinas experimentais de Química. Em relação a estas últimas, a carga horária varia de 210 a 600 h.

Nas disciplinas destinadas à formação pedagógica do licenciando, também ocorrem diferenças. Entretanto, é possível observar que estas disciplinas constituem uma porcentagem relativamente baixa do total de conteúdo científico-cultural. Esta é uma face importante da formação do licenciando, mas que parece não ser compreendida dessa maneira por algumas instituições.

Entendendo-se que as $1800 \mathrm{~h}$ de conteúdos científico-culturais competem fornecer ao licenciando tanto conhecimento pedagógico quanto químico (além de outros tipos de conhecimento que a instituição julgar necessário à formação de um professor de Química), percebe-se que, do total desta carga horária uma porcentagem acentuadamente maior é destinada às disciplinas de conteúdo químico, especialmente as de natureza teórica. Do total da carga horária de conteúdo científico-cultural, até $80 \%$ chega a ser destinada a essas

Tabela 1. Distribuição da carga horária nos cursos de licenciatura em Química das IES públicas paulistas, de acordo com o Parecer 28/2001

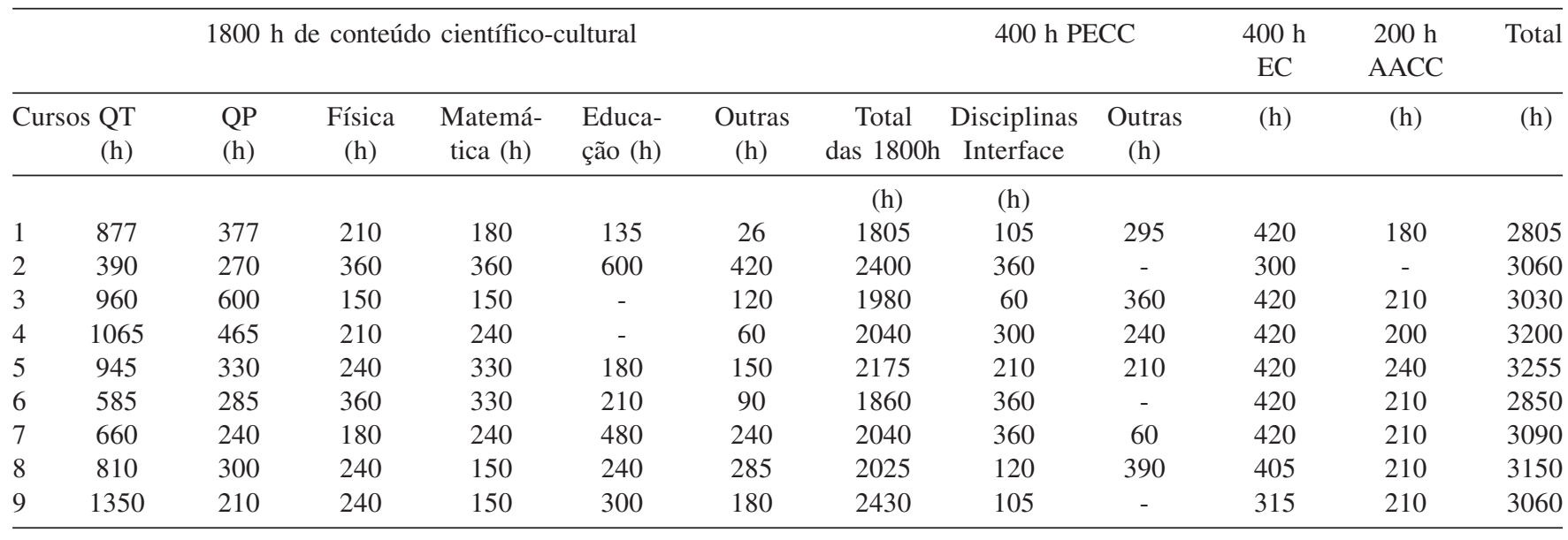


disciplinas - teóricas e práticas -, como é o caso do curso 3.

O conhecimento químico do professor é de importância fundamental, necessitando ir além dos conteúdos programáticos reservados ao ensino médio, visto que este tem que estar seguro de seu conhecimento para direcionar e facilitar a aprendizagem de seu aluno. Todavia, no processo de formação não se deve descuidar do conhecimento pedagógico, o qual é responsável por fornecer ao licenciando bases filosóficas, psicológicas e metodológicas para subsidiar o exercício de sua profissão. O curso 3, por exemplo, não reserva um espaço dos conteúdos científico-culturais para essa formação, transferindo-a para as atividades de PECC, as quais por sua vez, são deficientes em disciplinas voltadas para a interface Química/Educação. Por tratar-se de um caso extremo, este foi tomado como exemplo, entretanto, esse tipo de distorção acontece em outros cursos, como pode ser visto na Tabela 1 .

A partir dos dados da Tabela 1 e da Figura 1, algumas considerações podem ser tecidas a respeito de como a carga horária destinada às atividades de PECC foram distribuídas em cada curso. Analisando-se também os projetos pedagógicos e as grades curriculares utilizadas para que a Tabela 1 e a Figura 1 fossem construídas, é possível verificar que 5 cursos buscaram desenvolver essas $400 \mathrm{~h}$ de modo a obter os objetivos formativos propostos para tal. Nestes cursos, PECC está inserida dentro da carga horária de disciplinas pedagógicas e de conteúdo químico, sendo que neste acréscimo, os docentes responsáveis pelas disciplinas deverão estimular os licenciandos a desenvolver atividades que integrem conhecimentos da área de ensino com os conteúdos que estão sendo aprendidos em aulas de Química. Ou ainda, a carga horária corresponde a disciplinas que procuram realizar a interface entre os conteúdos pedagógicos e os químicos.

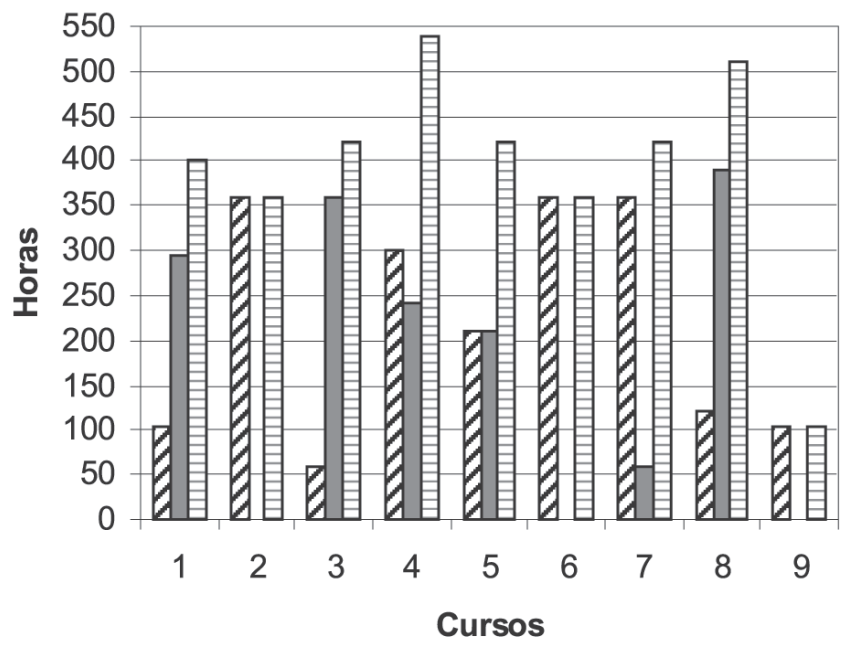

Figura 1. Distribuição das atividades de PECC nos cursos de licenciatura

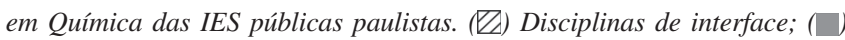
Outras disciplinas; ( $($ Total da carga horária de PECC

Entretanto, algumas distorções também foram notadas. Além do curso 3 , já discutido anteriormente e do curso 4 que semelhantemente não alocou disciplinas da área pedagógica nos conteúdos científico-culturais, no curso 8 , teoricamente 510 h são destinadas à PECC. Entretanto, desta carga horária, 390 h destinam-se a disciplinas teóricas e experimentais de conteúdo químico. No curso 9 , por sua vez, por não haver discriminação no projeto pedagógico ou na grade curricular a respeito das $400 \mathrm{~h}$ de PECC, foi possível encontrar, apenas, $105 \mathrm{~h}$ em disciplinas que buscam realizar a interface entre os conhecimentos pedagógicos e os químicos. Finalmente, diferentemente do que foi observado para a carga horária de disciplinas de conteúdo científico-cultural, na qual o total de horas extrapolou o mínimo estipulado de $1800 \mathrm{~h}$, quatro dos nove cursos não completaram $400 \mathrm{~h}$ de atividades de PECC.

$\mathrm{O}$ fato de que a carga horária de PECC está sendo suprimida em detrimento dos conteúdos químicos em alguns cursos conduz a uma reflexão que pode ser corroborada por alguns depoimentos registrados na pesquisa de mestrado que originou este artigo. Em tal pesquisa, detectou-se uma recorrente insegurança quanto à própria formação por parte dos formandos em cursos de licenciatura em Química - semelhantemente ao detectado por Lima para o curso de Pedagogia -, cuja solução não se encontra no acréscimo de disciplinas de conhecimento químico às grades curriculares. Tal insegurança refere-se à falta de preparo para realizar a transposição didática - já discutida anteriormente como uma das práticas a serem adquiridas na carga horária de PECC. Apesar de terem aprendido elevada quantidade de conceitos químicos, a preocupação dos futuros professores encontra-se em como organizar o conteúdo e utilizar metodologias de ensino que proporcionem aprendizagem para seus futuros alunos. Alguns trechos de depoimentos são transcritos abaixo para ilustrar a apreensão dos licenciandos. ${ }^{17}$

“Não. [O curso] Não preparou nada, nada, nada, nada. No primeiro mês eu pedia socorro. Eu corria pela universidade sabe, procurando algumas amigas professoras. Pelo amor de Deus, como é que você explicou mol pros seus alunos porque eu não consigo explicar, eles não entendem, então eu não sei explicar! (...) por exemplo, a gente não teve uma aula assim, olha vocês vão explicar mol desse jeito pros seus alunos, mas não é uma receita de bolo, mas uma discussão (...)".

“(...) Eu acho que o problema no meu curso é que a gente tem de um lado pedagogo e de outro lado químico. Não tem ninguém que faça a interface e não adianta querer pegar esse pessoal que tem 50 anos de trabalho em Pedagogia e fazer eles entenderem isso como uma coisa misturada. Eu acho que isso nunca vai funcionar. Eu acho que é por isso que o meu curso tem problema, porque vem o pessoal lá da Pedagogia, vem o pessoal daqui da Química. Eles não têm diálogo, é uma coisa totalmente separada (...)”.

"Nossa!! Não sei, juro que eu não sei. Não saberia. Não. Assim como preparar uma aula, não tenho idéia [aluno questionado a respeito de como prepararia uma aula para ensino médio]".

Pode-se perceber que os estudantes dos últimos anos do curso de licenciatura estão se tornando professores de Química inseguros quanto à dinâmica da sala de aula. As pesquisas em ensino de Química já apresentam metodologias de ensino diferenciadas com resultados promissores para a aprendizagem de conceitos químicos, mas que, entretanto, não chegam à maioria das discussões das salas de aula das universidades. Apesar da boa formação em relação ao conhecimento químico, os futuros professores não se sentem habilitados a traduzir esse conhecimento em uma linguagem compreensível a seus alunos.

Além disso, um discurso recorrente, mas pouco trabalhado entre os estudantes entrevistados para a pesquisa de mestrado foi o fato de eles entenderem não ser possível abandonar a metodologia tradicional de ensino, pois acreditam que as novas abordagens para o ensino de Química não são possíveis de serem aplicadas em uma sala de aula real, com 40 alunos em média. Pode-se estender a todas as disciplinas pedagógicas a baixa compreensão por parte do licenciando em relação a sua validade. Isso se deve ao fato de existirem poucos momentos, nos cursos de licenciatura em Química, 
de discussão a respeito da necessidade e importância da formação pedagógica para o exercício docente. A deficiência ainda persistente nos cursos de graduação em se compreender a teoria e a prática como processos que necessitam ser complementares - como explicado por Piconez e Pimenta - contribui para o não entendimento dos objetivos a que se destinam as disciplinas pedagógicas.

No que diz respeito aos estágios curriculares, quando comparados às cargas horárias de prática de ensino, há uma maior compreensão sobre essas atividades nesses cursos no sentido de que sua carga horária não foi tão deslocada para o aprendizado de conceitos químicos. Três dos nove cursos destinaram uma carga horária inferior a $400 \mathrm{~h}$ para os estudantes realizarem atividades de estágio curricular, contrariando o que preconiza o Ministério da Educação (MEC), como pode ser conferido na Figura 2.

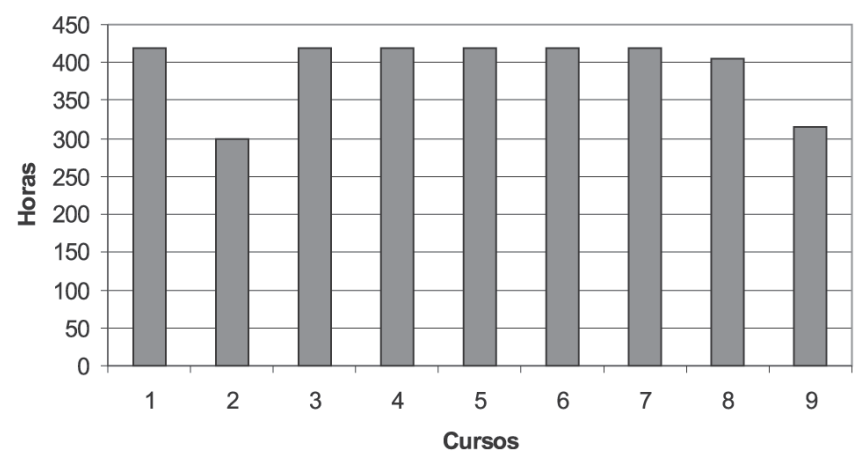

Figura 2. Carga horária de estágio curricular (EC) nos cursos de licenciatura em Química das IES públicas paulistas

Todavia, apenas na minoria dos cursos havia um planejamento institucional a respeito da melhor maneira de o estágio ser conduzido, buscando-se uma coerência entre as diversas disciplinas que contemplam esse tipo de atividade. Em se tratando dos discursos dos(as) coordenadores(as) dos cursos ouvidos nas entrevistas realizadas para a pesquisa de mestrado, ${ }^{17}$ apenas um deles demonstrou conhecimento claro sobre o planejamento e os objetivos a serem alcançados com esta carga horária. Esta pessoa também expôs a preocupação em propiciar ao estagiário uma evolução gradual de sua participação dentro de uma sala de aula, culminando com aulas ministradas a uma turma completa de ensino médio. Em contrapartida, vários coordenadores revelaram preocupação com a carga horária destinada à preparação do futuro professor de Química para a sala de aula, o que prejudicaria a "transmissão de conteúdos químicos" aos mesmos, como pode ser constatado com os seguintes trechos das entrevistas com os coordenadores de curso. ${ }^{17}$

“(...) agora tem muito modismo, acho que as pessoas têm que tomar muito cuidado com esse excesso de didatismo em detrimento do conteúdo, porque nós somos químicos (...)”.

“(...) eu não sei, eu acho que é a gente tem que ter... propostas novas eu acho que essa proposta do MEC, eu tenho um pouco de preocupação com esse número alto de horas de estágio né porque não sei se isso não é um exagero (...)".

Essa baixa compreensão a respeito dos objetivos do estágio pelos coordenadores sugere que provavelmente os estágios seguirão os mesmos moldes das antigas disciplinas PEES, estando a decisão a respeito do formato no qual serão desenvolvidos os está- gios mais a cargo do docente responsável por cada disciplina de estágio curricular que de um planejamento institucional.

Nessa perspectiva, tomando-se algumas opiniões de licenciandos formandos ${ }^{17}$ a respeito do antigo modelo em que se configurava o estágio supervisionado, pode-se dizer que os estágios de observação foram pouco apreciados por eles. Esses alunos justificaram essa concepção defendendo que o estágio de observação, por ter um fim em si mesmo, não acrescentava experiências significativas à sua formação docente.

O outro método largamente utilizado - os minicursos a alunos de ensino médio - era, na maioria dos cursos, legado à última semana do ano de estágio, não permitindo que houvesse uma conversa reflexiva a respeito das dificuldades e dúvidas geradas nessa atividade, como defendido por Schön. Um quesito comum aos cursos era o fato de maior segurança ser demonstrada pelo formando em assumir uma sala de aula, quanto maior era o contato que esse estudante tivesse com alunos de ensino médio. ${ }^{17} \mathrm{O}$ treinamento no preparo e no desenvolvimento de aulas para alunos de ensino médio também foi enfaticamente sugerido pela maioria dos licenciandos entrevistados ${ }^{17}$ para ser contemplado nos currículos de PECC e EC.

\section{CONSIDERAÇÕES FINAIS}

$\mathrm{O}$ fato de as atividades de PECC e EC estarem melhor distribuídas nas determinações do MEC, começando a ser ministradas desde o começo e a partir da segunda metade do curso respectivamente, poderá levar o licenciando a preocupar-se mais com sua prática docente e com as questões relativas a sua futura profissão. Isso porque os momentos dispensados para a formação do professor deixam de estar concentrados no último ano - como acontecia nos cursos antes da reformulação -, o que pode proporcionar ao licenciando ter contato com os diversos aspectos da atividade docente desde seu ingresso no curso, além de propiciar o desenvolvimento da sua prática reflexiva e do hábito de construir seu próprio conhecimento.

A dificuldade detectada entre os licenciandos entrevistados em lidar com as situações de sala de aula reforça a necessidade de os cursos de licenciatura concentrarem seus esforços nas atividades de prática de ensino com discussão e elaboração de atividades alternativas ao ensino tradicional. Durante as atividades de estágio seria desejável que utilizassem a observação, a leitura dessas observações e a prática da transposição didática, sobretudo integrando nessas atividades a aplicação de metodologias alternativas estudadas pelos pesquisadores da área educacional e reservando um espaço especial para a prática da reflexão a respeito das mesmas, dentro de situações reais de trabalho do futuro professor. Entretanto, o que pôde ser observado a partir dos direcionamentos tomados pelos cursos em geral, foi que a ênfase da instituição centra-se na aquisição de conhecimento químico, visto que a maioria dos cursos aqui analisados está sob responsabilidade de unidades químicas. ${ }^{18}$ Isso mostra os anseios dos químicos em formarem novos químicos, perdendo de vista os objetivos a que se propõe um curso de licenciatura, que é formar professor, num curso com suas próprias especificidades e necessidades, que devem ser compreendidas e executadas pelos sujeitos que atuam no curso. Retomando-se a aflição e a insegurança apresentada por vários licenciandos formandos a respeito da falta de preparo para assumir uma sala de aula e ensinar de modo a que seus alunos aprendam, pode-se dizer que as instituições, ao elaborarem suas grades curriculares com elevada carga horária de disciplinas de química, desconhecem ou desconsideram as necessidades e preocupações de seu público alvo. 


\section{REFERÊNCIAS E NOTAS}

1. Dall'orto, H. L. R.; Dissertação de Mestrado, Universidade Estadual de Campinas, Brasil, 1999.

2. Piconez, S. C. B. Em A prática de ensino e o estágio supervisionado; Piconez, S. C. B., org.; Ed. Papirus: Campinas, 2002.

3. Pimenta, S. G.; O estágio na formação de professores: unidade teoria e prática?, Cortez: São Paulo, 2002.

4. Schön, D. A.; The reflective practitioner: how professionals think in action, Basic Books: EUA, 1983.

5. Maldaner, O. A.; A formação inicial e continuada de professores de Química: professores/pesquisadores, Ed. Unijuí: Ijuí, 2003.

6. Lima, E. F.; Tese de Doutorado, Universidade Federal de São Carlos, Brasil, 1996.

7. Faingold, N. Em Formando professores profissionais: Quais estratégias? Quais competências?; Paquay, L.; Perrenoud, P.; Altet, M.; Charlier, E., orgs.; Artmed: Porto Alegre, 2001, p. 119.

8. Paquay, L.; Wagner, M. Em ref. 7, p. 129.
9. Perrenoud, P.; Altet, M.; Charlier, E.; Paquay, L. Em ref 7, p. 210.

10. Nardi, R.; Longuini, M. D. Em Pesquisas em ensino de ciências; Nardi, R.; Bastos, F.; Diniz, R. E. S., orgs.; Escrituras: São Paulo, 2004.

11. Fávero, M. L. A. Em Formação de professores: pensar e fazer; Alves, N., org.; Cortez: São Paulo, 1992.

12. http://portal.mec.gov.br/sesu/arquivos/pdf/00901formprof.pdf, acessada em Setembro 2005.

13. http://portal.mec.gov.br/sesu/arquivos/pdf/02801formprof.pdf, acessada em Setembro 2005

14. Faljoni-Alario, A.; Rossi, A. V.; Jorge, R. A.; Silva, A. B. F.; Oliveira, J. E.; Ferreira, L. H.; Rodrigues, R. M. B.; Quim. Nova 1998, 21, 674

15. http://portal.mec.gov.br/sesu/arquivos/pdf/130301Quimica.pdf, acessada em Setembro 2005.

16. Carvalho, J. S. F.; Programa de Formação de Professores - USP, USP: São Paulo, 2004

17. Kasseboehmer, A. C.; Dissertação de Mestrado, Universidade Federal de São Carlos, Brasil, 2006.

18. O termo 'unidades Químicas' refere-se aos Institutos de Química ou aos Departamentos de Química. 